\title{
Photo-mineralization of azo dye reactive yellow 145 in aqueous medium by $\mathrm{TiO}_{2}$-coated non-woven fibres
}

\author{
Said Alahiane 1,2, , Asma Sennaoui ${ }^{2}$, Fatima Sakr ${ }^{2}$, Mohamed Dinne ${ }^{2}$, Samir Qourzal ${ }^{2}$ \\ and Ali Assabbane ${ }^{2}$ \\ ${ }^{1}$ Laboratory of Analytical and Molecular Chemistry/LCAM, Department of Chemistry, Faculty Polydisciplinary \\ Safi, Cadi Ayyad University, Safi, Morocco \\ ${ }^{2}$ Catalysis and Environment Team, Department of Chemistry, Faculty of Science, Ibn Zohr University, Agadir, \\ Morocco
}

\begin{abstract}
This study aims the degradation of the Reactive Yellow 145 dye (RY 145), chosen as a model molecule in aqueous solution. Photocatalytic experiments have been conducted at ambient temperature in a lab-scale batch reactor, operating with $\mathrm{TiO}_{2}$ catalyst supported on paper in an aqueous medium. The ultraviolet irradiation was provided by using an artificial source. The evolution of the pollutant concentration has been followed over time by spectrophotometry and high-performance liquid chromatography (HPLC). The Mineralization and identification of reactive intermediates products were also studied. The results obtained indicate that $\mathrm{TiO}_{2}$ has the most interesting photocatalytic properties and that the measurement of the Chemical Oxygen Demand (COD) has an important abatement of the organic load of an order of $89.13 \%$. The identification of photoproducts helped to better understand the mechanism of the molecule attack by hydroxyl radicals.
\end{abstract}

Keywords: Photo-mineralization, RY 145 dye, UV-irradiation, $\mathrm{TiO}_{2}, \mathrm{COD}$.

\section{Introduction}

The synthetic dyes are widely used in the textile industry. Due to the inefficiency of the industrial dyeing process, 10 to $15 \%$ of the dyes are lost in the effluent during the dyeing processes, making them colourful $^{1}$. It is estimated that 280,000 tons of textile dyes are unloaded in these industrial effluents around the world each year ${ }^{2}$.

These dyes can pollute waterways and change the biological cycles, affecting the photosynthesis process. In addition, they can also threaten human health during extended contact with these products, that can induce toxic reactions such as skin sensitization (dermatitis) and also affect respiratory functions ${ }^{3,4}$.

The largest class of dyes used is Azo type, which comprises the Reactive Yellow dye145 (RY 145).

This class is typically characterized by the presence of one or more azo bond $(-\mathrm{N}=\mathrm{N}-)$ and the aromatic rings, which are considered to be toxic and mutagenic to living organisms ${ }^{5}$. The degradation of these azo dyes, which comprise about $70 \%$ of all dyes used, is difficult because of their complex structure and synthetic nature ${ }^{2,6}$.
These toxins are generally very poorly biodegradable. The Advanced Oxidation Processes (AOPs) are techniques that allow their total photo-mineralization (water processing, carbon dioxide and / or inorganic ions) ${ }^{7,8}$. Among these $\mathrm{AOP}_{\mathrm{S}}$, heterogeneous photocatalysis $\mathrm{TiO}_{2}$ appears as a potential and emerging solution for the removal of these compounds 9,10 .

This work aims to study the degradation kinetics of RY 145 dye by heterogeneous photocatalysis, using $\mathrm{TiO}_{2}$ immobilized on non-woven paper. Thus, the study of the photo-mineralization of pollutant by the COD measurement and the identification of intermediate by-products by chromatographic HPLC were examined, in order to suggest the degradation mechanism of RY 145 in aqueous solutions.

\section{Materials and methods}

\subsection{Reagents}

All reagents used in the experiments were of analytical grade and used as received. The tested dye is the RY 145; its molecular structure is shown in Fig.1. Its physical and chemical properties are summarized in Table 1. 


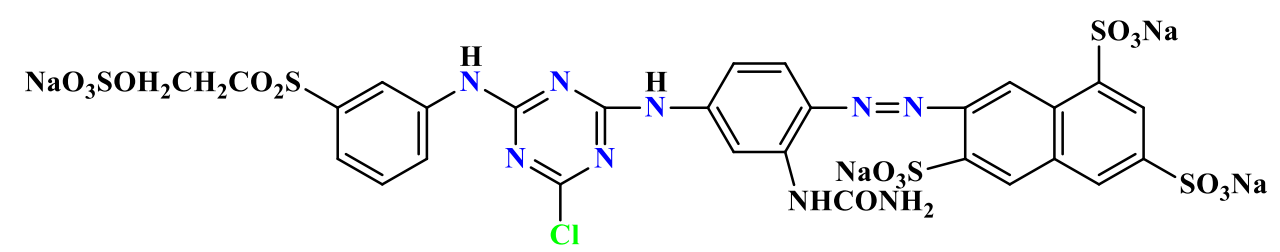

Figure 1. Structure of RY 145

Table 1. Physical and chemical properties of the studied dye.

\begin{tabular}{|c|c|}
\hline Dye & RY 145 \\
\hline Class & Azo day \\
\hline Family & Reactive dye \\
\hline Molecular formula & $\mathrm{C}_{28} \mathrm{H}_{20} \mathrm{ClN}_{9} \mathrm{O}_{16} \mathrm{~S}_{5} 4 \mathrm{Na}$ \\
\hline Molecular weight $(\mathrm{g} / \mathrm{mol})$ & 1026.25 \\
\hline Solubility in water $(\mathrm{g} / \mathrm{L})$ at $25^{\circ} \mathrm{C}$ & 80 \\
\hline$\lambda_{\max }(\mathrm{nm})$ & 419 \\
\hline Origin & Sigma-Aldrich \\
\hline Purity $(\%)$ & 99.9 \\
\hline
\end{tabular}

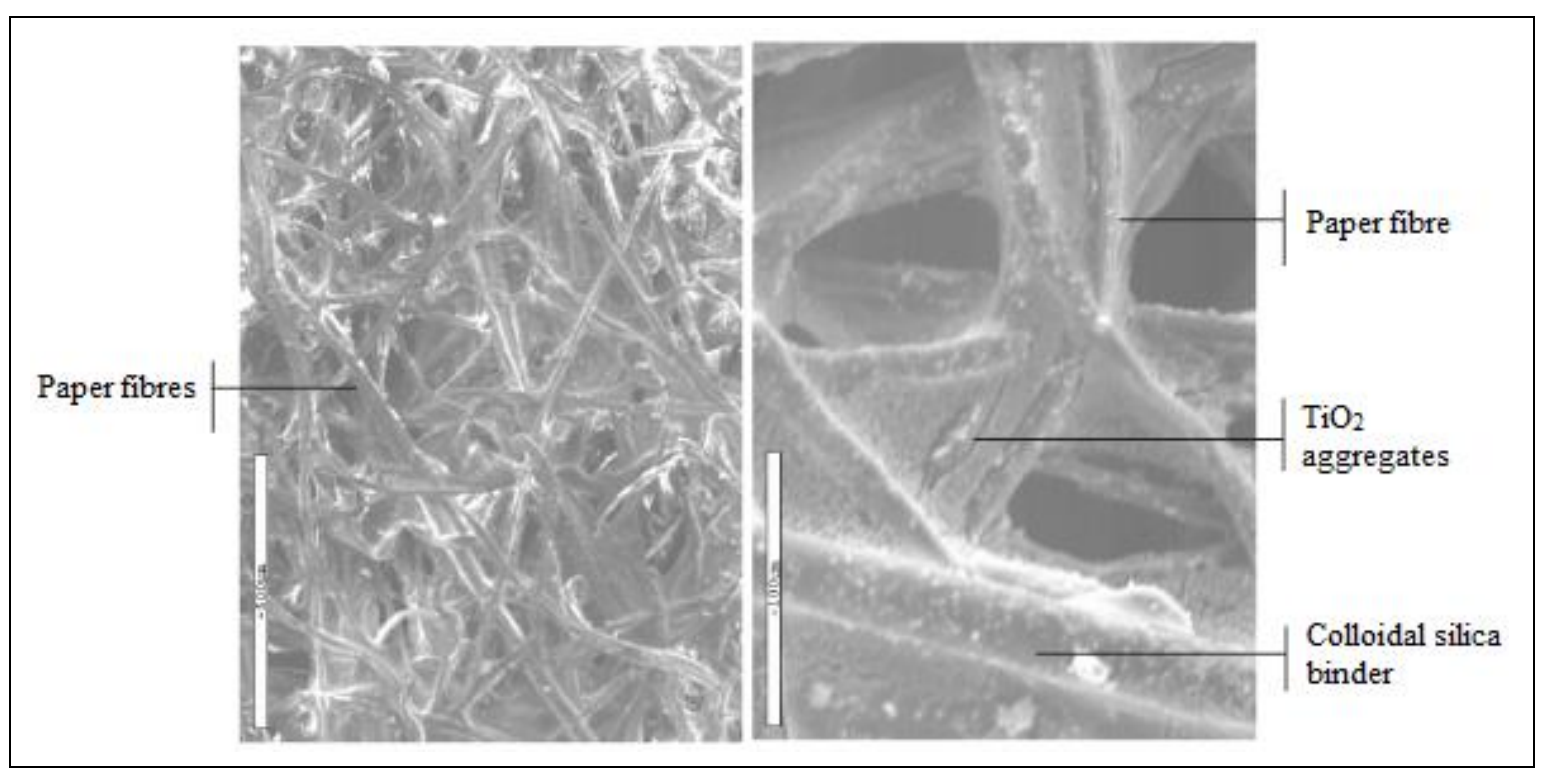

Figure 2. Scanning electron microscopy of the $\mathrm{TiO}_{2}$-coated non-woven fibres

Table 2. Main physicochemical properties of the photocatalyst $\mathrm{TiO}_{2}$ supported.

\begin{tabular}{|c|c|}
\hline Crystalline form & Anatase (> 99\%) \\
\hline Specific surface & $335 \mathrm{~m}^{2} / \mathrm{g}$ \\
\hline Weight & $75 \mathrm{~g} / \mathrm{m}^{2}$ \\
\hline Thickness & $254 \mu \mathrm{m}$ \\
\hline PC500 & $18 \mathrm{~g} / \mathrm{m}^{2}$ \\
\hline $\mathrm{SiO}_{2}$ & $20 \mathrm{~g} / \mathrm{m}^{2}$ \\
\hline Zeolite & $2 \mathrm{~g} / \mathrm{m}^{2}$ \\
\hline
\end{tabular}

The used photocatalyst $\left(\mathrm{TiO}_{2}\right.$ supported on paper), was provided by the firm Ahlstrom (France, ref 1048). It's about the titanium dioxide PC500 as Millennium inorganic chemicals brand. It is composed of natural and synthetic non-woven fibres, using an inorganic binder consisting of a colloidal dispersion of $\mathrm{SiO}_{2}$. Its 
chemical and physical properties are grouped in Table 2. The scanning electron microscope is illustrated in Fig.2.

The presence of zeolite on $\mathrm{TiO}_{2}$ surface leads to increasing the surface area of the photocatalyst, which is an effective way to create more reactive sites and better adsorption capacity and thus enhance the photocatalytic activity ${ }^{11}$. This support is tested by several research teams and seems gives good results 10,12

\subsection{Experimental apparatus}

The photocatalytic degradation tests were performed in a photochemical batch reactor with a capacity of

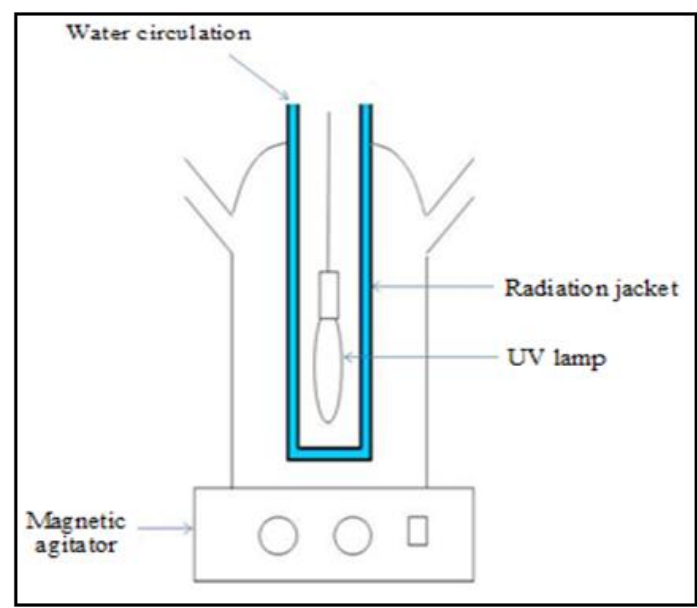

half a liter and that bears openings, one for taking samples, and the others are used for the introduction of oxygen (Fig.3). The radiation source is a mercury vapor lamp (HPK $125 \mathrm{~W}$ ), placed in a thermostat jacket cooled by a permanent water flow while eliminating the infrared radiation emitted by the lamp. The photocatalyst is bonded to the interior of the reactor. The photoreactor is then charged with $500 \mathrm{~mL}$ of the RY 145 dye solution, and maintained under continuous stirring for 1 hour before irradiation. This period is required to reach adsorption equilibrium of RY 145 on the surface of $\mathrm{TiO}_{2}$ photocatalyst. The initial $\mathrm{pH}$ of the solution is close to 5,8

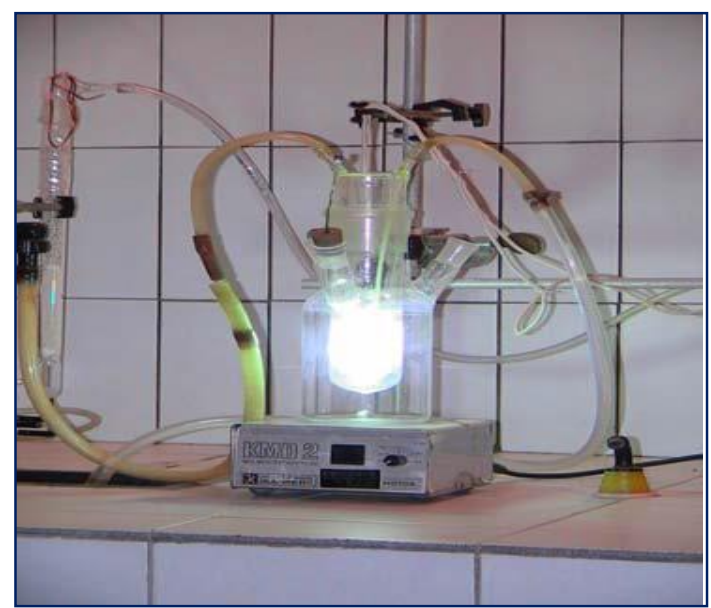

Figure 3. Schematic diagram of the catalytic photoreactor

\subsection{Experimental procedure}

All dye solutions used in this study were prepared by weighing and dissolving the required amount of RY 145 in distilled water. The samples taken during experiences are filtered by Millipore membrane filter type $0.45, \mu \mathrm{m}$ and analysed by different analytical techniques: UV/Visible spectrophotometry type Jasco series V-630, and high-performance liquidchromatography (Shimadzu LC-SPD20A). The eluent flow rate was maintained at $1 \mathrm{~mL} / \mathrm{min}$. The mobile phase is prepared by mixing of $70 \%$ : $30 \%$ of bidistilled water: acetonitrile. The wavelength of maximum absorption $\left(\lambda_{\max }\right)$ is $419 \mathrm{~nm}$. The COD measurements are performed by a Photometer-System MD200 at a wavelength of $420 \mathrm{~nm}$.

\section{Results and discussion}

\subsection{Disappearance kinetics of RY 145}

Photolysis phenomenon is one of the natural degradation pathways of a molecule when it is submitted to particular light radiation. The adsorption is a spontaneous phenomenon. These natural phenomena may have a non-negligible influence and can occur in parallel. In this case, they enter potentially in competition with the phenomenon of photocatalysis. The quantification of these phenomena has been carried out beforehand to the studies conducted with the catalyst.
The results are shown in Fig.4. In photolysis (without $\mathrm{TiO}_{2}$ ), the irradiation of the reaction mixture led to the disappearance of about $4 \%$ of the dye after 90 min of irradiation. The RY 145 absorbs virtually no radiation emitted by the lamp. It, therefore, appears that the contribution of the direct photolysis is negligible in a wavelength range close to $419 \mathrm{~nm}$. It means that the excitation of dye molecules by photon and then the dispersion of their excitation energy had no role on the decolourisation (reaction (1)) ${ }^{13}$ :

Dye + hv $\rightarrow$ NO Products

The batch adsorption experiments were carried out in the presence of $\mathrm{TiO}_{2}$ and under dark. It shows a decrease in the pollutant concentration from the first minutes of agitation. The results show maximum adsorption of $10 \%$ of the solute. This is due to the dye molecule adsorption on the surface. However, and as clearly indicated by the concentration profile in Fig.4, in the presence of $\mathrm{TiO}_{2}$ and UV-irradiation, a complete decolourisation of the dye was observed after 90 min of irradiation time.

These results confirm the photocatalysis nature of the chemical reaction. The $\mathrm{TiO}_{2}$ particles are the cause of this activation. They will absorb UV radiation to give rise to highly reactive species, such as hydroxyl radicals $\left(\mathrm{HO}^{\circ}\right)$, which will lead to the RY 145 dye degradation in solution ${ }^{14,15}$. 


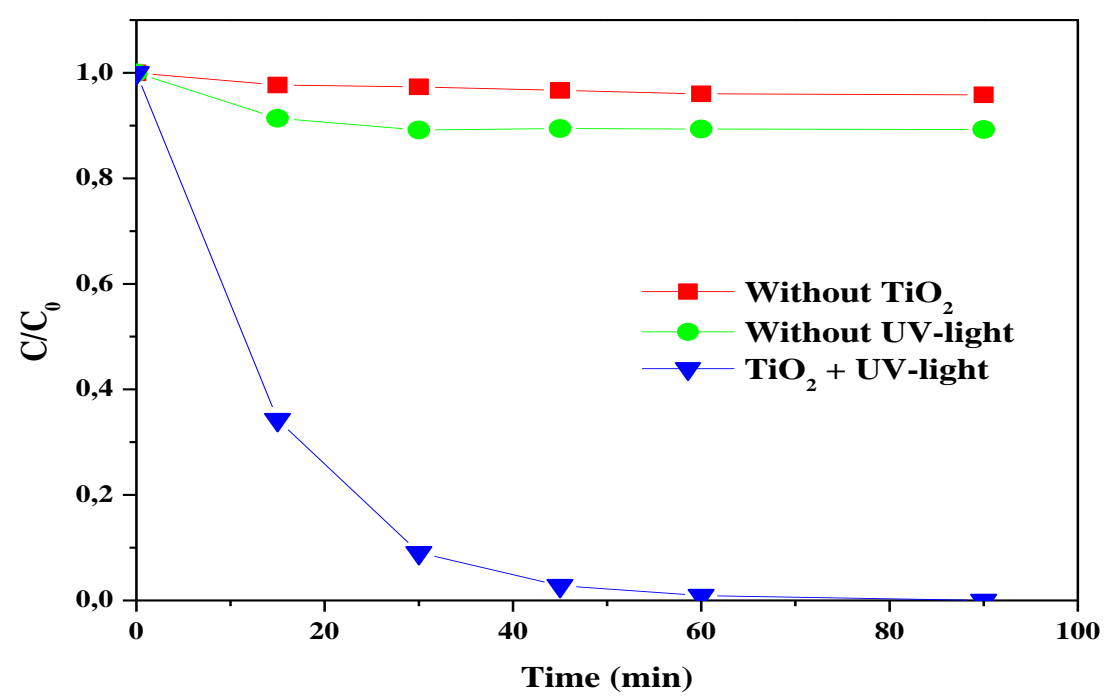

Figure 4. Direct photolysis, adsorption, and photocatalysis of RY 145 dye on $\mathrm{TiO}_{2}\left([\mathrm{RY} 145]=30\left(\mathrm{mg} \cdot \mathrm{L}^{-1}\right)\right.$

\subsection{Absorption spectrum}

The UV-Visible spectra of Reactive Yellow 145 dye solutions after different intervals of photodegradation, in the presence of $\mathrm{TiO}_{2}$-coated non-woven fibres, are shown in Fig.5. The RY 145 decolourisation showed that the chromophoric azo bond of the dye molecule is destroyed ${ }^{16}$. During the photocatalytic treatment, we observed the disappearance of the existing band in the UV wavelength range and the appearance of another absorbance band in the Ultraviolet part around $235 \mathrm{~nm}$. The complete decolourisation was achieved at $60 \mathrm{~min}$ of irradiation time, while the complete degradation requires a longer time ${ }^{16}$. The rapid dye decolourisation is due to the initial electrophilic cleavage of its chromophoric azo $(-\mathrm{N}=\mathrm{N}-)$ bonds attached to the naphthalene ring ${ }^{17}$. The degradation of the aromatic part of the dye molecule produced some intermediate products, and the removal of these intermediates took longer time ${ }^{18,19}$.

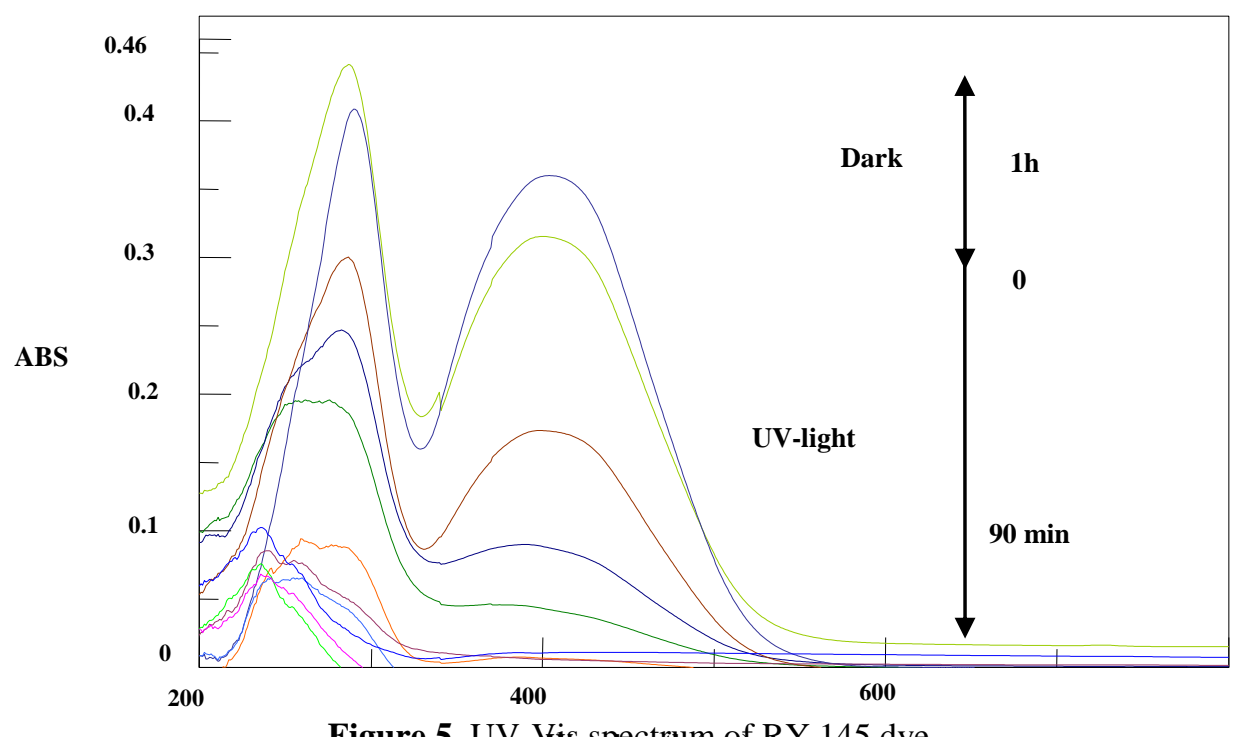

\subsection{Mineralization of RY 145}

Fig.6 explains the variation of the Abatement of the

Chemical Oxygen Demand (COD) versus degradation time of an aqueous solution of RY 145 (30 mg. $\left.\mathrm{L}^{-1}\right)$.

During the first hour of photoirradiation, a complete discoloration of the dye was obtained $(89.13 \%)$. At this stage, the COD reduction was of $23.91 \%$, which suggests that there were the intermediate products ${ }^{20}$. After 7 hours of irradiation, only $10.87 \%$ of COD remains. These results show that the chromophore groups of RY 145 are easily oxidizable, and the parent compound is degraded but not mineralized. Therefore, total mineralization requires a treatment time much more important than the discoloration.

Generally, the mineralization reaction of organic compounds can be summed up by the following reaction ${ }^{21}$ : 


$$
\mathrm{C}_{\mathrm{n}} \mathrm{H}_{\mathrm{a}} \mathrm{O}_{\mathrm{b}}+\mathrm{cCr}_{2} \mathrm{O}_{7}^{2-}+8 \mathrm{cH}^{+} \rightarrow 2 \mathrm{cCr}^{3+}+\mathrm{nCO}_{2}+\frac{a+8 c}{2} \mathrm{H}_{2} \mathrm{O}
$$

With, $c=\frac{2 n}{3}+\frac{a}{6}-\frac{1}{3} b$

Indeed, the mineralization reaction of RY 145 dye is as follows:

$$
\mathrm{C}_{28} \mathrm{H}_{20} \mathrm{O}_{16}+16,66 \mathrm{Cr}_{2} \mathrm{O}_{7}^{2-}+133,33 \mathrm{H}^{+} \rightarrow 33,32 \mathrm{Cr}^{3+}+28 \mathrm{CO}_{2}+76,64 \mathrm{H}_{2} \mathrm{O}
$$

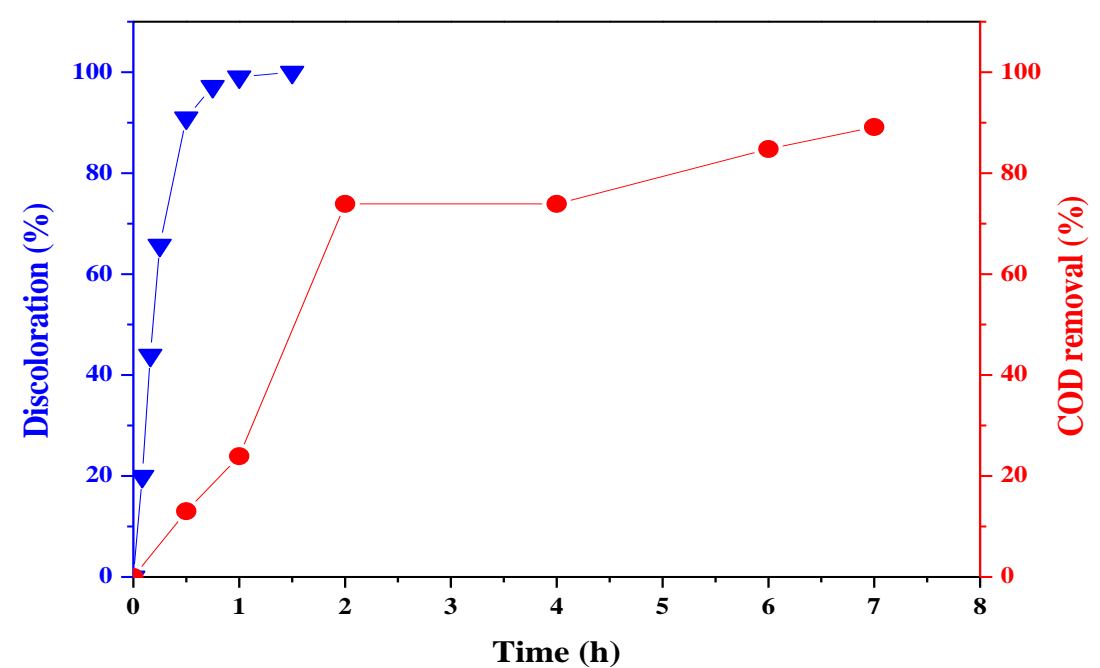

Figure 6. COD removal and discoloration of RY 145 dye

Table 3 summarizes the theoretical COD value, which has calculated by using a chemical reaction process ${ }^{21}$, and the experimental COD value of the initial concentration of the RY 145 dye.

\begin{tabular}{|c|c|c|}
\hline Initial concentration $\left(\mathbf{m g . L} \mathbf{L}^{-1}\right)$ & $\mathrm{COD}_{\text {th }}\left(\mathrm{mg}\left(\mathrm{O}_{2}\right) \cdot \mathrm{L}^{-1}\right)$ & $\mathrm{COD}_{\exp }\left(\mathrm{mg}\left(\mathrm{O}_{2}\right) \cdot \mathrm{L}^{-1}\right)$ \\
\hline 30 & 39.20 & 46 \\
\hline
\end{tabular}

Table 3. $\mathrm{COD}_{\text {th }}$ and $\mathrm{COD}_{\exp }$ values of RY 145 dye.

From the results mentioned in the Table 3, it appears that the COD value calculated theoretically is close to that obtained experimentally, which shows that this technique is reliable for determining COD. This result is similar to those observed by L. Zidani ${ }^{21}$.

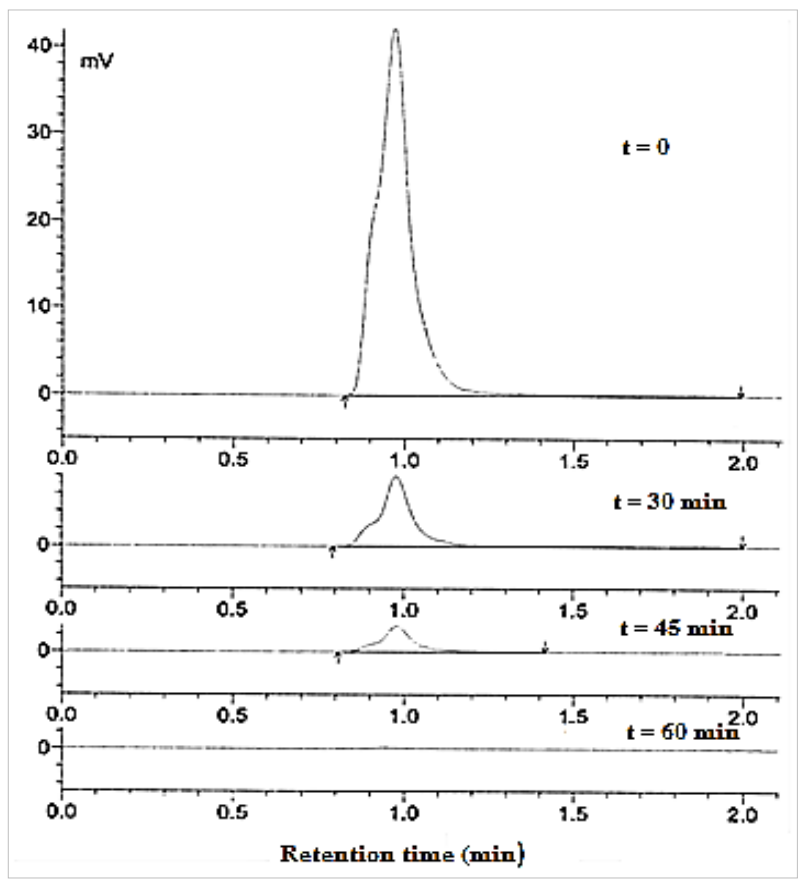

Figure 7. HPLC chromatograms of RY 145 during treatment by heterogeneous photocatalysis 


\subsection{Monitoring degradation of RY 145 dye by HPLC}

The chromatographic analysis has enabled to follow qualitatively the chemical evolution of aqueous solutions of azo dye RY 145, during treatment by heterogeneous photocatalysis process. The disappearance of the dye, following the oxidative action of hydroxyl radicals, is accompanied by the formation of aromatic intermediates. After their accumulation, up to a competitive concentration in the medium, these intermediates undergo in their turn oxidation by hydroxyl radicals.

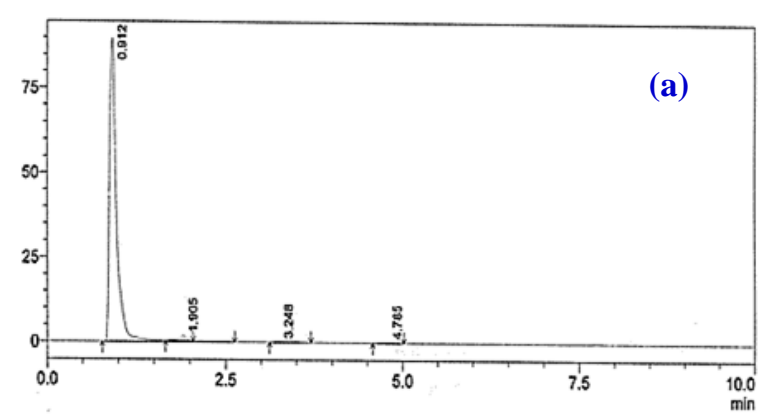

The Series of chromatograms related to RY 145 dye are represented on the Fig.7. These chromatograms are recorded at different times during a photocatalytic degradation.

\subsection{Identification of intermediate products}

From the chromatograms of different samples analyzed in the course of the photocatalytic degradation of RY 145 (Fig.8), it appears that they had many peaks of reaction intermediates. The detection is carried out at $235 \mathrm{~nm}$ for the intermediate formed during the photocatalytic degradation of this azo dye.

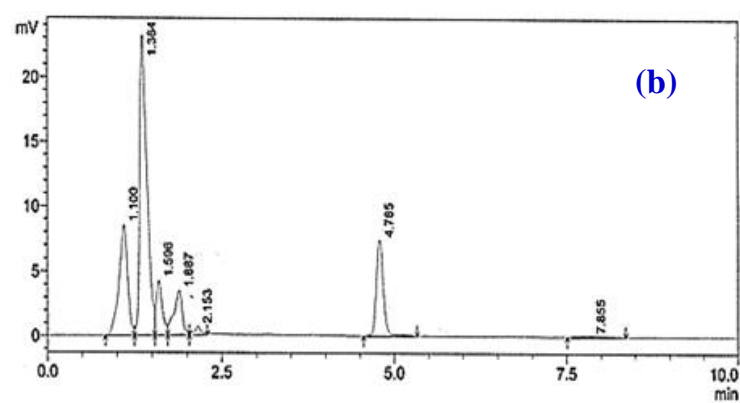

Figure 8. HPLC chromatograms (a) before irradiation and (b) after $3 \mathrm{~h}$ of irradiation

An analysis of the spectra of chromatograms determined by HPLC was performed to further identify the intermediate products in order to highlight the number of peaks (intermediate) that appear and disappear during the photochemical treatment process in the catalytic photoreactor. Then, in the same analytical conditions, the spectra of pure standards were determined. The by-products were identified by comparison of the retention time of the peaks corresponding to the intermediates formed during the photodegradation of RY 145 with the retention times of pure standards. This finding was confirmed by the addition method of the external standard to the sample, including the chromatogram that reveals the presence of the suspected element.

The choice of commercial standards is based on the form of the chemical structure of the dye and the possibilities of rupture at the level of the molecule. It appears that the characteristics of chromatograms of intermediates are consistent with those of some of the standards. Figure 9 below shows the evolution of peak areas of its products as a function the time of appearance (irradiation) for the RY 145 dye.

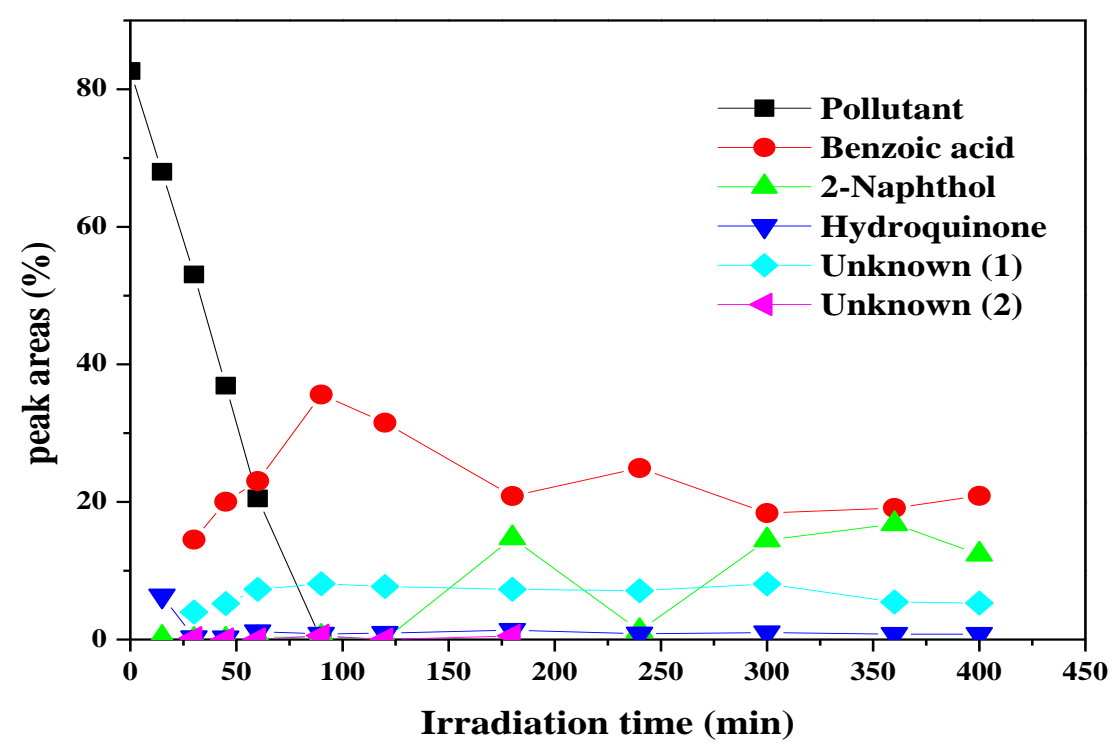

Figure 9. Evolution of intermediate products versus irradiation time during degradation of RY 145 


\subsection{Suggested decomposition mechanism of RY} 145

Based on the supposed intermediate identified as degradation by-products which were analyzed by
HPLC, and from the literature ${ }^{22-28}$, a simplified mechanism for RY 145 degradation in aqueous solution during treatment by heterogeneous photocatalysis is proposed in Fig. 10.

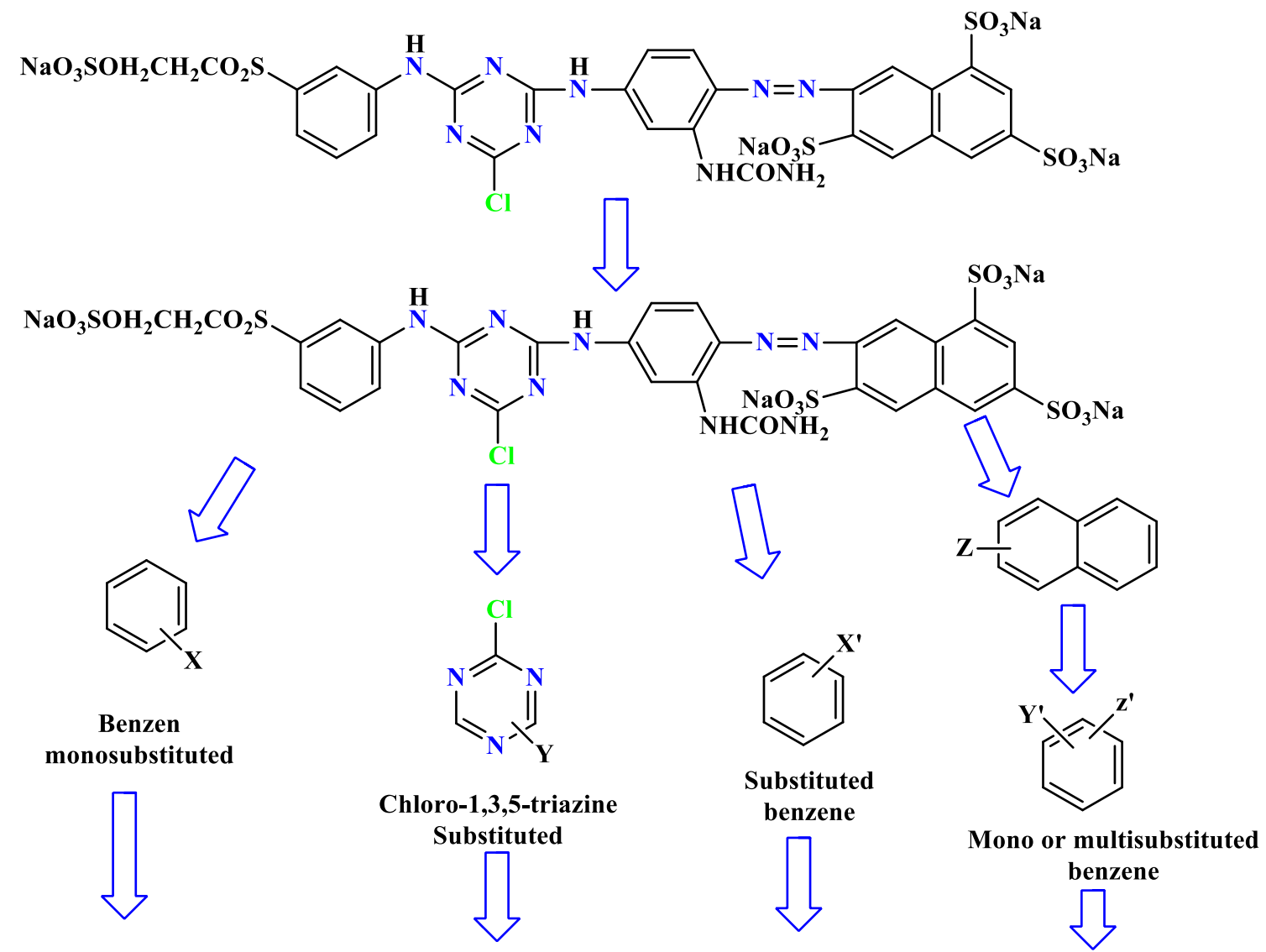

Carboxylic acid, aldehyde, formic acid, alcohol, hydrocarbon

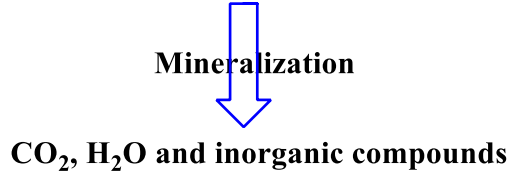

$X, Y, z, X^{\prime}, Y^{\prime}$ and $Z^{\prime}$ represent substituted grouping not identified completely

Figure 10. Proposed mechanism of the photocatalytic degradation of RY 145 dye

The change in UV-Vis spectrum in a first degradation time of RY 145 represents the reduction of the azo group $-\mathrm{N}=\mathrm{N}-$, which is transformed into hydroxyl structure and the subsequent oxidation leads to the cleavage of the $-\mathrm{N}-\mathrm{N}$ - bond, the formation of the nitro group, the production of benzene compounds and mono or multi substituted naphthalene. Next, the additional oxidation causes opening of the aromatic ring leading to the formation of alcohols, aldehydes and carboxylic acids ${ }^{9,29}$. Finally, the mineralization of the dye leads to carbon dioxide, water and inorganic compounds.

\section{Conclusion}

The study of the degradation and mineralization of
RY 145 has allowed showing the feasibility of treatment of azo dye by photocatalysis with coated $\mathrm{TiO}_{2}$ on paper fibres $\mathrm{TiO}_{2}$ in the presence of UV light and oxygen. The photocatalytic reaction aspect of the system studied $\left(\mathrm{TiO}_{2} / \mathrm{UV} / \mathrm{O}_{2}\right)$ resulted in discoloration followed by mineralization more or less complete, giving by-products to different chemical structures. Therefore, total photo mineralization requires a treatment time much more important than the discoloration. The by-products (reactive intermediates) detected by HPLC during the degradation of RY 145 dye were identified and compared to some pure standards by their retention times $\left(t_{R}\right)$ and are confirmed by injection of these standards during the analysis of test taken. 


\section{References}

1- L. Lian, L. Guo, C. Guo, Adsorption of Congo red from aqueous solutions onto Ca-bentonite, Journal of Hazardous Materials, 2009, 161, 126-131.

2- R. Maas, S. Chaudhari, Adsorption and biological decolorization of azo dye reactive red 2 in semicontinuous anaerobic reactors, Process Biochemistry, 2005, 40, 699-705.

3- F. A. Pavan, S. L. P. Dias, E. C. Lima, E. V. Benvenutti, Removal of Congo red from aqueous solution by aniline-propyl silica xerogel, Dyes and Pigments, 2008, 76, 64-69.

4- K. Yogendra, K. M. Mahadevan. N. Suneel, N. Madhusudhana,

Photocatalytic activity of synthetic $\mathrm{ZnO}$ composite against Coralene red $\mathrm{F}_{3} \mathrm{BS}$ dye in the presence of solar light, International Journal of Environmental Sciences, 2011, 1, 839-846.

5- S. Singh, K. Pakshirajan, A. Daverey, Enhanced decolourization of Direct Red - 80 dye by the white-rot fungi Phanerochaete chrysosporium employing a sequential design of experiments, Biodegradation, 2010, 21, 501-511.

6- V. P. Vesna, I. S. Sanja, R. N. Aleksandra, J. V. Sava, Adsorption of azo dyes on polymer materials, Hemijska Industrija, 2011, 67, 881-900.

7- M. A. Al Sawah, D. Richard, C. De Bellefon, J-M. Chovelon, C. Ferronato, Photocatalytic degradation of ammonium ions in the presence of doped $\mathrm{TiO}_{2}$, Comptes Rendus Chimie, 2010, 13, 502-507.

8- N. Barka, S. Qourzal, A. Assabbane, A. Nounah, Y. Ait-Ichou, Photocatalytic degradation of an azo reactive dye, Reactive Yellow 84, in water using an industrial titanium dioxide-coated media, Arabian Journal of Chemistry, 2010, 3, 279-283.

9- S. Qourzal, N. Barka, M. Tamimi, A. Assabbane, Y. Ait-Ichou, Photodegradation of 2-naphthol in water by artificial light illumination using $\mathrm{TiO}_{2}$ photocatalyst: Identification of intermediates and the reaction pathway, Applied Catalysis A, 2008, 334, 386-393.

10-N. Barka, S. Qourzal, A. Assabbane, Y. Ait-Ichou, Kinetic Modeling of the Photocatalytic Degradation of Methyl Orange by Supported $\mathrm{TiO}_{2}$, Journal of Environmental Science and Engineering, 2010, 4, 1-5.

11-H. Tong, S. Ouyang, Y. Bi, N. Umezawa, M. Oshikiri J. Ye, Nano-photocatalytic materials: possibilities and challenges, Advanced Materials, 2012, 24, 229-251.

12-K. Elatmani, H. Afanga, S. Qourzal, A. Assabbane, Y. Ait-Ichou, J. Costa Pereira, M. Emilia Azenha, Dégradation photocatalytique de deux insecticides Lannate et Carbaryl sur $\mathrm{TiO}_{2}$ supporté, Annales de Chimie-Science des Materiaux, 2011, 35, 269-282.

13-T. Soltani, M. H. Entezari, Photolysis and photocatalysis of methylene blue by ferrite bismuth nanoparticles under sunlight irradiation, Journal of Molecular Catalysis A: Chemical, 2013, 377, 197-203.

14-R. J. Tayade, T. S. Natarajan, H. C. Bajaj, Photocatalytic Degradation of Methylene Blue Dye Using Ultraviolet Light Emitting Diodes, Industrial \& Engineering Chemistry Research, 2009, 48, 10262-10267.

15-Y. Ji, L. Zhou, C. Ferronato, X. Yanga, A. Salvador, C. Zenga, J.M. Chovelon, Photocatalytic degradation of atenolol in aqueous titanium dioxide suspensions: Kinetics, intermediates and degradation pathways, Journal of Photochemistry and Photobiology A: Chemistry, 2013, 254, 35- 44.

16-S. Yang, R. Jin, Z. He, Y. Qiao, S. Shi, W. Kong, Y. Wang, X. Liu, An experimental study on the degradation of Methyl Orange by combining hydrodynamic cavitation and chlorine dioxide treatments, chemical engineering transactions, 2017, 59, 289-294.

17-M. Muruganandham, M. Swaminathan, Photocatalytic decolourisation and degradation of Reactive Orange 4 by $\mathrm{TiO}_{2}-\mathrm{UV}$ process, Dyes and Pigments, 2006, 68, 133-142.

18-K. Dai, H. Chen, T. Peng, D. Ke, H. Yi, Photocatalytic degradation of methyl orange in aqueous suspension of mesoporous titania nanoparticles, Chemosphere, 2007, 69, 1361-1367.

19-I. Bouzaida, C. Ferronato, J. M. Chovelon, M. El Baker Rammah, , J. M. Herrmann, Photocatalytic degradation of Reactive Yellow 23 in aqueous solutions containing $\mathrm{TiO}_{2}$ suspensions, Journal de la Société Chimique de Tunisie, 2012, 14, 29-38.

20-J. Radjenovic, C. Sirtori, M. Petrovic, D. Barceló, S. Malato, Solar photocatalytic degradation of persistent pharmaceuticals at pilot-scale: kinetics and characterization of major intermediate products, Applied Catalysis B: Environmental, 2009, 89, 255-264.

21-L. Zidani, Etude de la dégradation de quatre colorants azoïques par photocatalyse comparaison avec d'autres procédés d'oxydation avances (POAs). Ph. D. Thesis. Faculty of exact sciences, University of Batna, Algeria, Algeria, 2009.

22-H. Z. Zhao, Y. Sun, L. N. Xu, J. R. Ni, Removal of Acid Orange 7 in simulated wastewater using a three-dimensional electrode reactor: Removal mechanisms and dye degradation pathway, Chemosphere, 2010, 78, 46-51. 
23-I. K. Konstantinou, T.A. Albanis, $\mathrm{TiO}_{2}$-assisted photocatalytic degradation of azo dyes in aqueous solution: kinetic and mechanistic investigations: a review, Applied Catalysis B, 2004, 49, 1-14.

24-C. M. Ma, G. B. Hong, H. W. Chen, N. T. Hang, Y. S. Shen, Photooxidation Contribution Study on the Decomposition of Azo Dyes in Aqueous Solutions by VUV-Based AOPs, International Journal of Photoenergy, 2011, 8, 1-8.

25-S. Song, X. Xu, L. Xu, Z. He, H. Ying, J. Chen, Mineralization of CI Reactive Yellow 145 in Aqueous Solution by Ultraviolet-Enhanced Ozonation, Industrial \& Engineering Chemistry Research, 2008, 47, 1386-1391.

26-L. M. Ahmed, F. T. Tawfeeq, M. H. A. AlAmeer, K. A. Al-Hussein, A. R. Athaab, PhotoDegradation of Reactive Yellow 14 Dye
(A Textile Dye) Employing $\mathrm{ZnO}$ as Photocatalyst, Journal of Geoscience and Environment Protection, 2016, 4, 34-44.

27-M. Sleiman, D. Vildozo, C. Ferronato, Photocatalytic degradation of azo dye Metanil Yellow: optimization and kinetic modeling using a chemometric approach, Applied Catalysis B: Environmental, 2007, 77, 1-11.

28-M. A. Behnajady, N. Modirshahla, N. Daneshvar, Photocatalytic degradation of an azo dye in a tubular continuous-flow photoreactor with immobilized $\mathrm{TiO}_{2}$ on glass plates, Chemical Engineering Journal, 2007, 127, 167-176.

29-Z. He, C. Sun, S. G. Yang, Y. C. Ding, H. He, Z. L. Wang, Photocatalytic degradation of Rhodamine $\mathrm{B}$ by $\mathrm{Bi}_{2} \mathrm{WO}_{6}$ with electron accepting agent under microwave irradiation: mechanism and pathway, Journal of Hazardous Materials, 2009, 162, 1477-1486. 